2018-09

\title{
Surf zone hazards and injuries on beaches in SW France
}

Castelle, B

http://hdl.handle.net/10026.1/11995

10.1007/s11069-018-3354-4

Natural Hazards

Springer Verlag

All content in PEARL is protected by copyright law. Author manuscripts are made available in accordance with publisher policies. Please cite only the published version using the details provided on the item record or document. In the absence of an open licence (e.g. Creative Commons), permissions for further reuse of content should be sought from the publisher or author. 

Michel Campagne $^{8}$, Thibault Cavailhes ${ }^{1,2}$, Pierre Lechevrel ${ }^{2}$

4

$5 \quad{ }^{1}$ CNRS, UMR EPOC, Univ. Bordeaux, Pessac, France

${ }^{2}$ Univ. Bordeaux, UMR EPOC, Pessac, France

${ }^{3}$ School of Biological, Earth and Environmental Sciences, UNSW Sydney, Australia

8

${ }^{4}$ INSERM, ISPED, Centre INSERM U1219 Bordeaux population health research, France

$9{ }^{5}$ Univ. Bordeaux, ISPED, Centre INSERM U1219 Bordeaux population health research, France

${ }^{6} \mathrm{CHU}$ de Bordeaux, Pôle Urgences adultes, SAMU-SMUR, France

${ }^{7}$ Coastal Processes Research Group, School of Biological and Marine Sciences, University of Plymouth,

12 Plymouth, UK

${ }^{8}$ Emergency Medical Service SAMU-SMUR, Hospital Centre Côte Basque, Bayonne, France 


\section{Abstract}

Surf zone injuries (SZIs) are common worldwide, yet limited data is available for many geographical regions, including Europe. This study provides the first preliminary overview of SZIs along approximately $230 \mathrm{~km}$ of hazardous surf beaches in SW France during the summer season. A total of 2523 SZls over 186 sample days during the summers of 2007, 2009 and 2015 were analysed. Documented injury data included date and time; beach location; flag colour; outside/inside of the bathing zone; age, gender, country and home postal code of the victim; activity; cause of injury; injury type and severity. Injuries sustained ranged from mild contusion to fatal drowning, including severe spinal injuries, wounds and luxation. While the most severe injuries (drowning) were related to rip currents, a large number of SZIs occurred as a result of shore-break waves $(44.6 \% ; n=1125)$ and surfing activity $(31.0 \% ; n=783)$ primarily inside and outside of lifeguard patrolled bathing zones, respectively. Victims were primarily French living more than $40 \mathrm{~km}$ from the beach $(75.9 \%$ of the reported addresses; $n=1729)$, although a substantial number of victims originated from Europe $(14.7 \%$ of the addresses reported; $n=335)$, including The Netherlands (44.2\%; $n=148)$, Germany $(26.3 \% ; n=88)$ and Belgium (12.5\%; $n=49)$. The predominant age group involved in the incidents was between 10-25 years $(54.5 \% ; n=1376)$ followed by $35-50$ years $(22.6 \% ; n=570)$, with the majority of SZls involving males $(69.6 \%, n=1617)$. Despite the large predominance $(74.1 \% ; n=33)$ of males involved in the most severe drowning incidents, all of which occurred outside the bathing zone, a surprisingly large proportion of females $(48.0 \% ; n=133)$ experienced milder drowning incidents involving only minor to moderate respiratory impairment, peaking at 58.2\% $(n=85)$ within the age group 10-25. The spine/cervical injury population is very young, with $58.5 \%(n=313)$ within the age group $10-20$. Specific injuries tended to occur in clusters (e.g. rip current drowning or shore-break injury) with particular days prone to rip-current drowning or hazardous shore-break waves, suggesting the potential to predict level of risk to beachgoers based on basic weather and marine conditions. This study calls for increased social-based beach safety research in France and the development of more effective public awareness campaigns to highlight the surf zone hazards, even within a supervised bathing zone. These campaigns should be targeted towards young males and females, in order to reduce the number of injuries and drownings occurring on beaches in SW France.

Keywords: surf zone hazards; drowning; spinal injuries; rip currents; shore break; surfing 


\section{Introduction}

Sandy beaches are an attractive and natural playground for the millions of people who visit them each year worldwide. Beachgoers represent a diverse demographic group and visit beaches for a variety of recreational activities including sun bathing, swimming and wading, bodyboarding and surfing (West, 2005). However, despite their attractive qualities, beaches can also be dangerous environments. This is particularly true of beaches characterised by waves breaking at the shoreline and across a wide surf zone, where dangerous wave conditions and strong currents pose a threat to those beachgoers entering the water (Short and Brander, 2014; Short and Weir, 2016; Castelle et al., 2016a). Although it is not possible to estimate the number of beach related injury and drowning incidents globally, lifeguards rescue tens of thousands of people in distress each year and beach related fatal drownings worldwide are easily in the hundreds (Gilchrest and Branche, 2016). Each surf drowning is associated with significant emotional, societal and economic costs and in the case of serious near drowning or surf-related injuries, may also involve lifetime medical costs (Sherker et al., 2008).

It is now well established that the main cause of fatal drowning and lifeguard rescue on surf beaches globally are rip currents (e.g. Gensini and Ashley, 2009; Brighton et al., 2013; Arozarena et al., 2015; Brander and Scott, 2016). These strong, narrow, often channelised seaward flows of water (Figure 1a) originate within the surf zone and sometimes extend well beyond the seaward extent of breaking waves (Castelle et al., 2016a). Rip currents flow at speeds often exceeding $0.5 \mathrm{~m} / \mathrm{s}$ (MacMahan et al., 2006; Dalrymple et al., 2011; Castelle et al., 2016a) easily capable of carrying unsuspecting bathers of all swimming abilities (Drozdzewski et al., 2012; 2015) into deeper water where, in the worst case scenario, a combination of exhaustion and panic can ultimately result in a drowning death (Brander et al., 2011). There has been a recent increase in interest in the rip current hazard (see Castelle et al., 2016a for a review), in particular numerous studies have taken a socio-physical approach to profile beachgoer behaviour (Ballantyne et al., 2005; Sherker et al., 2010; Williamson et al., 2012; Woodward et al., 2013; Houser et al., 2016), their understanding and recognition of rip currents (Hatfield et al., 2012; Caldwell et al., 2013; Brannstrom et al., 2014) and how people may escape rip currents when caught in one (McCarroll et al. 2014, 2015; Castelle et al. 2016b; Van Leeuwen et al., 2016). This approach has yielded valuable information assisting development of future educational interventions related to the rip current hazard (Bradstreet et al., 2014; Houser et al, 2017).

\section{Fig1 comes here}

Figure 1: Primary hazards to recreational beach users, with all photographs taken in SW France: (a) rip currents, strong, narrow seaward flows through the surf zone capable of carrying bathers offshore often leading to drowning (Ph. Y. Lavigne); (b) dangerous shore-break waves, occurring mostly at high 
tide, with the potential to cause severe spinal injuries (Ph. J. Lestage); (3) body boarding, body surfing and particularly surfing are popular activities potentially causing impact injuries e.g. wounds, joint dislocation, head and cervical spine injuries (Ph. @Lacanausurfinfo.com).

However, despite this understandable focus on rip currents there are other risks to beachgoers. For instance, on steep beaches the rapid transition from deep to shallow water results in plunging/dumping wave conditions at the shore break that are associated with concentrated and intense wave impact. In these conditions (Figure 1b), being knocked over and tumbled in the shallow breaking waves can cause severe spine injuries (Robles, 2006; Puleo et al., 2016). Injuries resulting from surfing and body boarding (Figure 1c) are also recognized to occur more frequently in shore-break conditions (e.g. Beratan and Osborne 1987; Chang et al., 2006; Barucq et al. 2009; Hay et al., 2009). Even away from the shore break, surfing is far from a safe pastime with a wide spectrum of spinal pathologies sustained whilst surfing (Dimmick et al., 2013; Nathanson, 2013) as well as lacerations/cuts (Moran and Webber, 2013).

In comparison to the rip current hazard, there has been much less research on surf zone impact injury and similar surf zone related risks and exposure (Pikora et al., 2012; Puleo et al., 2016; Doelp et al., in press) and most of these have been restricted to the Delaware coast in the United States. There is clearly a need for studies throughout a variety of other regions and countries to examine and gain insight into the range of coastal hazards causing surf zone injuries (SZIs) as well as victim demographics. This knowledge can ultimately be used to assist in the development and dissemination of more effective local or generic prevention interventions.

The south-west coast of France hosts hundreds of kilometres of attractive sandy surf beaches. This region is also renowned for its pleasant climate through the year, especially the warmer summer months. Each summer approximately 10-15 million people visit the Aquitaine coast in SW France (Brumaud, 2016), many of whom enter the water thus exposing themselves to surf zone hazards. Each summer, on the order of a thousand to a few thousands of recreational water users are injured in the surf zone, with injuries ranging from mild contusion to fatal drowning, but more commonly spinal injuries of varying severity, wounds and luxation (Lapaty, 2004). However, like many other coastal regions globally, little is known about the epidemiology of summer SZIs along this coast.

The aim of this study is to provide a preliminary description and insight into SZIs along an approximately $230 \mathrm{~km}$ section of surf beaches in SW France. The study location and injury data collection are described in Sections 2 and 3, respectively. Results are presented in Section 4 and are further discussed in Section 5 with respect to global implications of the findings.

\section{Study location}


The study area located in SW France extends from the Adour estuary in the south to the Gironde estuary in the north (Figure 2). This $230-\mathrm{km}$ stretch of coastline is interrupted by the large-scale Arcachon inlet separating the Landes and Gironde coasts in the south and north, respectively (Castelle et al., 2018; Figure 2). The landscape essentially consists of relatively straight sandy beaches backed by high and wide coastal dunes. The coast is exposed to high-energy ocean waves generated in the North Atlantic Ocean coming from the W-NW direction, with a summer-mean significant wave height of $1.1 \mathrm{~m}$ and occasional summer events exceeding $3 \mathrm{~m}$ (Castelle et al., 2017). The coast is mesomacrotidal with a mean tidal range of approximately $3 \mathrm{~m}$.

It is estimated that approximately 4-5 million tourists, primarily from France and other European nations, come to the Gironde and Landes coasts each year to enjoy the beach (Brumaud, 2016). The coast hosts some of the finest surfing beaches in Europe attracting many surfers of all abilities. The coast is characterized by only a small number of coastal resorts providing direct access to the beach. Apart from these resorts, beaches are mostly accessed through coastal dune tracks from inland carparks. Some of these access points lead to beaches patrolled by lifeguards with a designated and supervised bathing zone, but many access points are situated on unpatrolled sections of beaches, kilometres away from any lifeguard presence, a scenario also described by McKay et al. (2014) in New South Wales, Australia.

\section{Fig2 comes here}

Figure 2: (a) France with location of the 10 largest cities and box showing study location; (b) study location between the 2 large black circles with the $230 \mathrm{~km}$ length of coast being dominated by highwave energy sandy beaches with the Arcachon lagoon tidal inlet delimiting the Landes and Gironde coasts. Grey squares indicate coastal municipalities where incident/injury report forms were gathered. (c) Aerial photograph showing the typical beach-dune landscape and wave conditions in SW France with prominent rip current channels apparent (Ph. V. Marieu).

\subsection{Primary surf zone hazards}

The beaches of SW France are characterised by strong rip currents (Bruneau et al., 2011) with mean flow speeds reaching $1 \mathrm{~m} / \mathrm{s}$ even in relatively low wave energy conditions $(<1 \mathrm{~m}$ wave height;Castelle et al., 2016b). Channelised rip currents (Castelle et al., 2016a) are common (Figure 1a) and the mesotide range $(\sim 3 \mathrm{~m})$ modulates breaking wave patterns and rip current flow throughout the tide cycle (Bruneau et al., 2009). On average, rip current channels are spaced $400 \mathrm{~m}$ alongshore and rip current activity is maximized between low and mid-tide. Other rip types (Castelle et al., 2016a) can form during other stages of the tide cycle, but are much less common than channelised rip currents. At, or near, 
high tide, waves can break close to the shoreline on the steepest beach sections creating hazardous shore-break conditions (Figure 1b). During busy summer months, large numbers of surfers of all ability, including surf schools, congregate in many areas away from the bathing zones. In crowded conditions, surfers are exposed to additional hazards as the risk of collisions is increased (Figure 1c).

\section{Injury data collection}

The beaches of the $230 \mathrm{~km}$ Aquitaine open coast are patrolled by lifeguards from May to September each year, with most of the (less popular) beaches patrolled only in July and August. Unlike other countries, many of the lifeguards are from the general reserve of the French National Police, namely the Compagnies Républicaines de Sécurité (CRS), who are in charge of general security missions including crowd and riot control. CRS are typically trained in anti-insurrection and anti-riot techniques, but some are also cross trained and serve as lifeguards on beaches in summer. For each patrolled area, CRS work together with civil lifeguards under the responsibility of a CRS chief lifeguard. Each coastal municipality along the coast (grey squares in Figure $2 \mathrm{~b}$ ) is responsible for the security of their stretch of coast that can cover up to approximately 20 kilometres (Lège, Figure $2 b$ ). The stretch of coast under the responsibility of a coastal municipality can include one or several supervised bathing areas, each delimited by 2 blue flags, typically extending no more than $100 \mathrm{~m}$ alongshore. The beach is also patrolled both to the north and to the south of the bathing area, although bathing is forbidden in these areas. Some coastal municipalities, which cover a long stretch of coast, also have completely unpatrolled areas. The bathing zone is typically located on a shore-connected shoal away from rip currents that flow through deeper channels. Beaches are patrolled from 11AM to 7PM although lifeguards often train along the beach before and after the patrolled hours.

Lifeguards are responsible for performing surf rescues and enforcement of beach ordinance. They also respond to medical emergencies and provide medical first aid before medical services arrive at the beach. During patrol hours, a flag is hoisted on a 10+ $\mathrm{m}$ mast with the colour indicating the level of risk: (1) green flag means that bathing is watched with no particular danger; (2) yellow-orange flag means that bathing is dangerous, but watched; and (3) red flag means that bathing is forbidden. Red flags are usually hoisted due to high waves and dangerous surf, but also due to pollution or lightning. Overall, the yellow orange flag is hoisted more than $85 \%$ of the time along Gironde and Landes coasts (Lapaty, 2004).

Whenever a medical incident occurs on the beach, a lifeguard responds to the scene to provide patient care and to potentially assist paramedics. The CRS chief lifeguard is responsible for ascertaining information about the incident including patient information and surf conditions at the time of the incident. Since the summer of 1999, a report is filed for every incident that occurs on the beach during 
the lifeguard season and all incident reports are stored at lifeguard headquarters (Lapaty, 2004). At the end of each summer, copies of the accident/injury incident report forms (Figure 3) are sent to the CRS SW France headquarters and to the Emergency Medical Service SAMU-SMUR of the Hospital Centre Côte Basque. In contrast with SZI report forms designed in other countries (e.g. Muller, 2018), rip currents are not pre-defined as a check box. Instead, rip-current related incidents were deduced from the indication of drowning and the comments provided in the "Accident description" box indicating that the beachgoer was caught in a rip current, as for each drowning incident the causes and circumstances were given in detail.

To save time in the data collection process, not all variables listed on report forms and filled in by the lifeguards (Figure 3) were entered into our database. Variables examined were as follows: date; beach location (municipality); start time of the incident; flag colour; accident inside or outside of the bathing zone; age; gender; country and home postal code of the victim; activity (wading/swimming, surfing, bodyboarding, other); cause of injury (rip current, shore break, collision against someone else, collision against their board, collision against someone else's board, falling, other); injury type (drowning, wound/contusion, spine/cervical, fracture/luxation, other), and additional comments if relevant to the injury. In case of a drowning incident, the drowning stage was also provided according to a 4-stage classification widely used in France (Menezes and Coasta, 1972; Dupoux et al., 1981): (1) exhaustion, but no sign of aspiration of water; (2) moderate respiratory impairment, anxiety; (3) altered consciousness, severe respiratory impairment or acute pulmonary oedema, tachycardia or hypotension; (4) coma, respiratory or cardiac arrest. Only incidents that occurred in the surf zone were gathered in the dataset.

Unfortunately, large data gaps exist essentially because the forms have not been properly archived and stored, sometimes including entire lifeguard seasons, making it impossible to analyse temporal trends of SZIs. Although we did our best to retrieve as much data as possible both at the CRS SW France headquarters and at the academic health centre of Bayonne, data from only 8 lifeguard seasons were collected (out of 17), 3 of which were incomplete. In this study, data from the 3 most recent full summer seasons were analysed. The 2 other full summer seasons (2000 and 2001) were disregarded to focus on the more recent SZIs statistics. This dataset consists of 2523 incident report forms gathered over a total of 186 individual calendar days during the summers of 2007, 2009 and 2015. Of these, $99.6 \%$ describe incidents that occurred in July or August, with only 12 calendar days in July/August having no form reported along the entire coast. Dataset limitations will be discussed in Section 5.

\section{Fig3 comes here}


Figure 3: An example of a CRS lifeguard incident/injury report form used in SW France. In this example, information that is used (blue) and not used (light grey) for the data collection and further analysis is indicated.

\section{Results}

217

Reports were obtained from all 23 municipalities shown in Figure $2 b$, with the municipality of the busy coastal resort of Lacanau providing the largest amount of data $(14.7 \% ; n=371)$. Figure 4 provides an overview of SZI types including primary cause and beachgoer activity at time of incident. Drowning (from stage 1 to 4 ) only covers $11.1 \%(n=281)$ of the injuries (Figure 4a). The most common injury type is fracture/luxation (33.6\%; $n=847)$ followed by wound/contusion $(20.3 \% ; n=511)$ and spine/cervical injuries $(18.6 \% ; n=470)$. Various other injuries were also reported $(16.4 \% ; n=413)$ such as minor pains that did not require any assistance. Shore-break waves are the most important cause of SZIs (44.6\%; $n=1125$, Figure 4b), of which can be added impacts with other wading people $(6.4 \% ; n$ $=162$ ) that primarily occur in shore-break waves in crowded bathing zones. Figure $4 \mathrm{~b}$ shows that another large proportion of injuries are related to surfing $(31 \% ; n=783)$ and bodyboarding $(5.3 \% ; n=$ 134) activities as evidenced by the large proportion of injuries caused by collision against their board (19\%; $n=479)$, someone else's board $(2.3 \% ; n=68)$ and falling $(10.1 \% ; n=254)$, although the latter involves a majority of wading beachgoers. Wading/swimming is the most common activity recorded in the incident/injury report forms (61.2\%; $n=1543$, Figure 4c).

\section{Fig4 comes here}

Figure 4: Surf zone incidents related to: (a) injury type; (b) primary cause; and (c) activity.

Figure 5 shows the distribution of SZls according to age and gender for the entire dataset (Figure 5a) and for specific activity, primary cause and injury type (other panels in Figure 5). Figure 5a shows that, overall, males were most frequently injured, comprising $69.6 \%(n=1617)$ of the entire sample. The distribution of age group within gender was non-normal, with on average injured females being younger than males. The median and mean age was 24 (19) years and 28.3 (26.0) years for males (females), respectively. Two age groups stand out in particular: i) $10-25$ years (39.5\% females, 60.5\% males) representing $54.5 \%(n=1376)$ of the dataset; and ii) $35-50$ years ( $30.7 \%$ females, $69.3 \%$ males) representing 22.6\% ( $n=570$; Figure 5a). Similar age/gender distributions are observed for swimming/wading activity (Figure 5b) and shore-break related injuries (Figure 5c). In contrast, the population injured while surfing is younger with $62.6 \%(n=490)$ within the age group $10-25$. Of note, the spine/cervical injury population is even younger with $58.5 \%$ ( $n=313$, Figure $5 \mathrm{e}$ ) within the age group 10-20. Within the age group 10-25 of the drowning population (all stages included), which is associated with $52 \%$ of the drowning incidents, the majority were females $(58.2 \% ; n=85)$ in contrast 
with all the other gender distributions. Table 1 provides more insight into the drowning population and shows that there is a large majority $(74.1 \% ; n=33)$ of males involved in severe drowning incidents (stages 3 and 4), while milder drowning incidents (stages 1 and 2) are approximately equally distributed between males and females. Overall 79\% $(n=222)$ of the drowning incidents are caused by rip currents, a proportion that ranges from 50\%-82\% depending on the drowning stage (Table 1 ).

\section{Fig5 comes here}

Figure 5: Age and gender distribution of SZIs for: (a) all incidents; and specific activity, primary cause and injury type: (b) wading/swimming; (c) shore break; (d) surfing; (e) spinal injuries; and (f) fatal and non-fatal drowning.

Table 1. Drowning incidents as related to gender, location (inside or outside of the bathing zone) and rip currents. The gender of 1 out of the 14 stage 3 drowning victims was not filled in the form.

\begin{tabular}{|l|l|l|l|l|l|l|}
\hline $\begin{array}{c}\text { Drowning } \\
\text { stage }\end{array}$ & Total & \multicolumn{1}{|c|}{ Male } & Female & $\begin{array}{c}\text { Inside } \\
\text { bathing zone }\end{array}$ & $\begin{array}{c}\text { Outside } \\
\text { bathing zone }\end{array}$ & Rip current \\
\hline 1 & 26 & $10(38 \%)$ & $16(62 \%)$ & $16(62 \%)$ & $10(38 \%)$ & $19(73 \%)$ \\
\hline 2 & 223 & $114(51 \%)$ & $109(49 \%)$ & $91(41 \%)$ & $131(59 \%)$ & $183(82 \%)$ \\
\hline 3 & 14 & $8(62 \%)$ & $5(38 \%)$ & $6(43 \%)$ & $8(57 \%)$ & $7(50 \%)$ \\
\hline 4 & 18 & $15(83 \%)$ & $3(17 \%)$ & $0(0 \%)$ & $17(100 \%)$ & $13(76.5 \%)$ \\
\hline Total & $\mathbf{2 8 1}$ & $\mathbf{1 4 7 ( 5 2 \% )}$ & $\mathbf{1 3 3 ( 4 8 \% )}$ & $\mathbf{1 1 3 ( 4 0 \% )}$ & $\mathbf{1 6 6 ( 6 0 \% )}$ & $\mathbf{2 2 2}(\mathbf{7 9 \% )}$ \\
\hline
\end{tabular}

Figure 6 shows the hourly variation of SZIs. 93.6\% ( $n=2362)$ of injuries occurred during patrolled hours, peaking at $18.9 \%$ ( $n=533$ ) between $4-5$ PM with the majority of injuries $(51.8 \% ; n=1357)$ occurring between 3-6PM. While there is no significant hourly variation in the injured gender distribution, $56.4 \%$ ( $n=368$ ) of injuries in the morning and early afternoon (before 2PM) are related to surfing activities. This is largely because: i) beaches are not yet crowded with beachgoers enjoying swimming and wading; ii) surf schools typically provide surf training courses in the morning and early afternoon; iii) offshore wind conditions, which greatly improve surf-break quality, generally occur early in the day before the onshore marine sea breeze picks up.

\section{Fig6 comes here}

Figure 6: SZI occurrence as a function of time and as a function of (a) gender and (b) activity.

Overall, $48 \%$ ( $n=1210$ ) of SZIs occurred inside the bathing zone, albeit with large variabilities of injury type (Figure 7). A large proportion $(81.8 \% ; n=418$ ) of wound/contusion injuries occurred outside of the bathing zone. This is due to these injuries being sustained primarily when surfing $(73.4 \% ; n=375)$ 
and because $100 \%$ of the injuries related to surfing occurred outside of the bathing zone as surfing is forbidden in these zones. Of interest, Figure 7 also shows that spine/cervical and fracture/luxation injuries primarily occur inside the bathing zone. This is because spine/cervical $(73.8 \% ; n=347)$ and fracture/luxation $(66.4 \% ; n=562$ ) are primarily sustained in the shore break, and because $74.1 \%(n=$ 834) of shore-break-related injuries occur inside the bathing zone. These findings highlight that shore breaks are clearly a major hazard in the bathing zone when beachgoers enter the water. Finally, a substantial amount $(40 \% ; n=113)$ of drowning incidents occur inside the bathing zone. However, 94.7\% ( $n=107$ ) of these drowning incidents were of mild severity (stages 1 and 2, see Table 1 ), and no fatal or stage 4 drowning occurred in the bathing zone in this dataset. This is presumably because water is shallow and water users are close to shore favouring self-rescue and enabling supervising lifeguards to react quickly to incidents.

\section{Fig7 comes here}

Figure 7: Percentage of SZI types inside (blue) and outside (red) of the bathing zone.

The number of SZls per day was highly variable in the dataset, with some days having no incident reports and others with a large number of SZIs. August 182007 received the highest number of incidents (60) with a proportion of primary causes and injury types roughly in line with the overall dataset presented above. More interesting were the second and third days with the highest number of SZIs. August 42009 and August 202009 were characterized by 59 and 52 SZIs, respectively. Both days were dominated by injuries caused by the shore break corresponding to $81.4 \%$ and $76.9 \%$ of the incidents, respectively. This demonstrates that the shore break can be highly hazardous to swimmers and that widespread incidents can occur even inside the bathing zone during particular days. Other days were also particularly prone to drowning due to rip currents. August 52007 was the day with the highest number of drowning incidents (17; 14 stage 2, 1 stage 3 and 2 fatal stage 4 ) corresponding to $45.9 \%$ of incident forms filled in that day.

Beach location and home postal code for each victim allowed a systematic quantification of the distance between the French victim and the beach. Overall, $85.3 \%(n=1943)$ of the victims were French when postal address was provided $(90.3 \%, n=2278)$. Although it is not possible to comment on the beachgoing frequency of the victims, those living within $40 \mathrm{~km}$ from the beach where the injury occurred were subjectively described as 'locals' and those beyond that distance described as 'nonlocals' as they typically have more than a half-hour drive from their home to the beach. Approximately $89 \%$ ( $n=1729)$ of French victims were non-locals, while $90.6 \%(n=2064)$ of all victims were non-locals. Figure 8 shows that $13.3 \%(n=335)$ of victims were European (non-French) with the most common countries of origin being The Netherlands (44.2\% of non-French European; $n=148$ ), followed by Germany (26.3\% of non-French European; $n=88$ ) and Belgium (12.5\% of non-French European; $n=$ 
49), which are all coastal countries, albeit with different wave climate and surf zone current conditions to SW France. Figure 9 provides more insight into the geographical distribution of the French victims. Peaks clearly identify the victims from the closest and largest French cities shown in Figure 2a with, for instance, victims from the nearby large cities of Bordeaux and Toulouse standing out. These patterns are consistent for both wading/swimming and surfing activities (Figure 9).

\section{Fig8 comes here}

Figure 8: Geographic distribution of SZIs in SW France (from patient home postal code).

\section{Fig9 comes here}

Figure 9: Distribution of the distance between the beach and patient home (from postal code) as a function of activity.

\section{Discussion and conclusions}

The patterns of SZIs along the high wave energy sandy beaches of SW France show some clear similarities with findings in other countries. The predominant age group involved in the incidents was between $10-25$ years, the majority of SZIs (69.6\%) involved males, and most victims were non-locals, which is consistent with trends found elsewhere (UK: RNLI, 2014; USA: USLA, 2015; Australia: SLSA, 2017). The three primary causes of SZIs found in this study, namely rip currents, shore break and surfing activity, which were mostly treated separately in other studies (e.g. Barucq et al., 2009; Brighton et al., 2013), are also clearly identified as the three primary hazards to recreational beachgoers in SW France. The major difference here is that these three primary hazards were addressed together in relation to SZI type, allowing a better assessment of the relative proportions and severity, which is critical to making more informed decisions about funding and targeting public safety programs. Wading was also identified to be the dominant activity associated with SZI (61.2\%), also consistent with other studies (e.g. 50.1\% on the Delaware beaches, Doelp et al., in press).

Some findings in this study are inconsistent with observations along other coasts. An example is the large proportion of females (48\%) involved in drowning incidents on beaches in SW France. This is in contrast to all existing drowning epidemiology studies (Brighton et al., 2013; USLA, 2015; SLSA, 2017), which highlight the large predominance of young males in drowning incidents. Indeed a recent beach safety educational campaign by Surf Life Saving Australia has focussed on targeting young males (https://sls.com.au/voung-men-risk-getting-caught-dying-rip-currents/). Although beyond the scope of this study, the physical, social and cultural reasons why young females are highly exposed to drowning incidents in SW France should be explored further. Both males and females within the age group between 35-50 years old were also found to be the second most common age group receiving 
SZIs, similarly to the anomalous and unexplained peak in the 35-55 age of SZIs reported along the Delaware coast (Puleo et al., 2016). Reasons to explain this are also unclear, although it is possible that somewhat older children are more likely to be less supervised by 35-55 aged parents and that declining physical fitness place middle aged adults at high risk. This can also be the signature of the vulnerable "weekend warriors" (Roberts et al., 2014), a category of people, most likely middle-aged, who are active, but not on a regular basis and tend to engage in demanding recreational sporting activities at similar intensities to when they were aged in their 20s. This can also be due to the beach user demographic, which will be discussed later. Finally, contrary to other studies performed along coastlines with a large range of wave exposures and different beach types (e.g. Arozarena et al., 2015), there was little spatial variation in in SZI data along the quasi-straight sandy coast of SW France.

The fact that shore-break waves are the most important cause of SZIs (44.6\%) is also somewhat surprising as this is not the case in other countries where rip currents are by far the primary cause ( 81 \% USA (USLA, 2015); 57.4 \% Australia (Brighton et al., 2013); 45 \% UK (RNLI, 2014)). Contrary to SW France, shore-break waves are typically associated with a low proportion of surf zone hazards in most of existing studies (8.5 \% Australia (Brighton et al. 2013); UK $16 \%$ (RNLI 2014)). Notable exceptions can occur, such as along the steep beaches of the Delaware coast where shore-break waves are identified as the primary surf zone hazard (Puleo et al., 2016; Doelp et al., in press), although the proportion with respect to the other surf zone hazards was not quantified. The beaches of SW France are, however, not particularly steep except near high tide, which limits the temporal duration of, and exposure to, hazardous shore-break conditions (Masselink and Short, 1993). Clearly the link between tide/beach slope and shorebreak injuries should be investigated further, but is beyond the scope of the present study. Finally, although the SW coast of France is known to attract many surfers, both from France and other European countries, the rate of SZIs related to surfing activity is surprisingly high (31\%) compared to elsewhere. For instance, only $3 \%$ of SZIs are related to surfing activity along the Delaware coast (Doelp et al., in press), behind body surfing (13.3\%) and body boarding (18.4\%). Although this was not quantified here, a large proportion of the injuries associated with surfing activity occurred during learn to surf courses as often indicated by the accident description in the incident/injury report forms.

The results of this study are similar to those of Puleo et al. (2016) in that there were particular days with high numbers of SZIs suggesting that there may be causal relationships with specific physical conditions relating to waves, tidal stage, and beach morphology and weather conditions and water temperatures that influence beach attendance and water entry, and therefore beachgoer exposure. Puleo et al. (2016) attempted to relate injury occurrence to environmental factors (including in-situ wave height, tidal stage and foreshore slope measurements) and found only weak correlations, but noted that the highest injury rates were associated with moderate wave height $(0.6 \mathrm{~m})$. In the absence 
of clear correlations, they suggested that SZI rates are likely related to human factors. In contrast, Scott et al. (2014) used 5-year lifeguard incident records from 20 beaches in southwest England together with wave and tide data and further found high correlations between environmental factors and riprelated rescues. They also showed considerable environmental control on mass rescue events. Physical conditions at the time of the injury such as wave height, period and direction, tidal stage, beach slope, water and air temperatures, wind and insolation were not recorded in the lifeguard incident forms addressed herein. However large-scale numerical weather and wave hindcast data are available along this stretch of coast (e.g. Masselink et al., 2016), along with data collected at nearby weather stations, which can be used instead. However, with the exception of regular topographic data collected at Truc Vert beach (Castelle et al., 2017), which is located approximately $15 \mathrm{~km}$ south of Le Porge on the Gironde coast (Figure 2b) and not representative of all the beaches along the coast, beach slope data is unavailable. There are some qualitative findings which suggest that rip-current and shore-break related injuries preferably occur around low and high tide, respectively, both for low- to moderateenergy waves. However, the detailed analysis is beyond the scope of this paper due to the apparent complexities in the relations between forcing and injury types, and this will be the subject of a future study as a key contribution of this effort is to demonstrate the relative contributions of different SZI types. The development of a risk predictor for a given surf zone hazard, which has been fairly successful in other countries using approaches of varying complexity (e.g. Lushine, 1991; Austin et al., 2013; Moulton et al., 2017) would clearly have beneficial implications for lifeguard management and beachgoer safety along the coast of SW France. Similarly, further investigation is needed to provide an accurate assessment of beachgoer demographics and beach usage in general, which is a critical component of any risk predictor, but remains a challenge for all beach safety related research (Brander, 2018).

Our results have other strong implications in terms of beachgoer management and safety. First, as most severe drowning incidents and all fatal drownings occurred well away from the bathing zones, the safety message "swim between the flags" during the patrolled season must be better communicated to the public. Second shore-break conditions are clearly highly hazardous, even within the patrolled bathing zone, particularly during specific days as described above. These shore-break related injuries can be severe. For example, one of the two stage- 4 drowning deaths in the summer of 2015, a healthy middle-age male, occurred in the shore break away from the bathing zone and was diagnosed with a severe whiplash and subsequent drowning. However, to our knowledge, educational interventions about dangerous shore-break conditions are non-existent in SW France. The lack of shore-break education and awareness has been pointed out in other studies. For instance, even on severely rated shore-break beaches in the US with dedicated shore-break warning signs less than $20 \%$ 
of the beachgoers actually saw the warnings (Doelp et al., in press). In addition to posting shore-break warning signs at relevant locations, a shore-break awareness campaign is clearly required in SW France to limit severe injuries so that beachgoers understand that, even inside the bathing zone, wading and swimming may not be safe. Third, rip currents clearly represent a major hazard to beachgoers in SW France, and are by far the leading deadly surf zone hazard. Although some rip-current educational interventions exist, they are not as well-developed, coordinated, prevalent or effective as they are in other countries such as the US, Australia and the UK (Brander and Scott, 2016). Given that $85 \%$ of the rip current drowning victims along the SW Coast were French, a strong need exists for a national rip current education program building on the lessons gained from other countries (e.g. Houser et al., 2017).

Our study has a number of limitations common to other beach safety related studies. First, accurate incident reporting of beach related injuries is a global challenge (Williamson, 2006) and as stated earlier in this paper, although the lifeguards were efficient in reporting, many reports were subsequently lost since 1999 making it impossible to conduct a robust SZI analysis throughout the last 17 years. Accordingly, the years 2007, 2009 and 2015 may not be entirely representative of the variability in SZIs in SW France. While improving incident reporting amongst lifeguards is a global challenge, in France a first step is to properly archive and store the data. Second, our results show that there is a reasonably low proportion of SZls related to rip currents, although rips are by far the leading deadly hazard in the dataset. However, it is important to note that rip-current related rescues were filled in only when drowning incidents occurred. The numerous timely and efficient rip-current rescues performed by lifeguards and by bystanders (Scott et al., 2014; Attard et al., 2015; Moran et al., 2017) were therefore ignored. The rip current hazard is therefore largely under-represented here.

The fact that the spine/cervical injury population along the SW Coast of France is very young, with 58.5\% within the age group 10-20, warrants further investigation. For instance, personal communication with local lifeguards indicates that lifeguards are more cautious with young people, with any suspicion of spinal injury typically being recorded as a spine injury in the forms, which would not be the case with an adult. Finally, although it is a strong limitation of all the epidemiology studies of SZIs, it is important to emphasize that the demographic profile of beachgoers is largely unknown. For instance, the 35-55 age group peak may just be the signature of a higher proportion of middle aged beach visitors. Another related issue is the exposure rate, which depends on the number of people who enter the water when they are at the beach, which is variable in time and space and is virtually unknown. Therefore, addressing the demographics and exposure of beachgoers is a paramount to further understand the epidemiology of SZIs (Woodward et al., 2013). Finally, due to lack of suitable data, we are unable to relate our findings to social factors such as beachgoer behaviour, visitation 
patterns, and water entry intentions in relation to flags and signage, similar to recent social based surf

440 hazard research (e.g. Brannstrom et al.,2015; Barlas and Beji, 2016; Houser et al., 2016). Such a study

441 is clearly needed and would provide valuable socio-cultural insights into French and European 442 beachgoers in comparison with those in other countries.

443 Regardless of these limitations, our study provides the first overview of SZIs in SW France. Injuries sustained range from mild contusion to fatal drowning and included severe spinal injuries, wounds and luxation. While the most severe injuries are related to rip currents, a large number of SZIs occurred as a result of shore-break waves and surfing activity primarily inside and outside of lifeguard patrolled bathing zones, respectively, with patterns differing from those reported elsewhere. We found a predominance of young males in the reported SZIs and severe drowning incidents, and a surprisingly high number of females. This calls for the development of improved awareness campaigns in France on rip currents and shore-break waves that are particularly targeted towards young males and females in order to reduce the number of injuries and drownings occurring on beaches in SW France. These campaigns should always emphasise the importance of bathing only between the flags and in the presence of lifeguards.

\section{Acknowledgments}

455

We thank the CRS headquarters for providing the forms as well as the lifeguard chiefs for filling the incident forms throughout the years. This work was assisted through funding provided by the IDEX "Invited Scholar" scheme (Univ. Bordeaux) that brought RB in Bordeaux in fall 2014 to initiate this research. The surf zone injury report forms, which still used at the time of writing this paper, were designed by J.M. Campagne in 1999 in close collaboration with CRS and civil lifeguards, fire brigade and coastal municipalities. BC funded by project SONO (ANR-17-CE01-0014) from the Agence Nationale de la echerche (ANR). The data file was declared upon the Commission Nationale Informatique et Liberté (CNIL) under the number 21118123v0 according to French law. This retrospective study was authorized by local ethic committee. We thank the two anonymous reviewers for constructive comments and suggestions that improved the paper.

\section{References cited}

Arozarena, I., Houser, C., Echeverria, A.G., Brannstrom, C., 2015. The rip current hazard in Costa Rica. Nat. Haz., 2, 753-768.

Arun Kumar, S.V.V., Prasad, K.V.S.R., 2014. Rip current-related fatalities in India: a new predictive risk scale for forecasting rip currents. Nat. Haz., 70, 313-335.

Attard, A., Brander, R.W., Shaw, W.S., 2015. Rescues conducted by surfers on Australian beaches. Accid Anal Prev., 82:70-8. 
Austin, M.J., Scott, T.M., Russell, P.E., Masselink, G., 2013. Rip current prediction: development, validation, and evaluation of an operational tool. Journal of Coastal Research, 29(2), 283-300.

Ballantyne, R., Carr, N., Hughes, K., 2005. Between the flags: an assessment of domestic and international university students' knowledge of beach safety in Australia. Tourism Management, 26(4), 617-622.

Barlas, B., Beji, S., 2016. Rip current fatalities on the Black Sea beaches of Istanbul and effects of cultural aspects in shaping the incidents. Natural Hazards, 80(2), 811-821.

Barucq, G., Jenkins, O., Mokni, T., Marce, S., Campagne, J.M., Le Jeune, D. 2009. Surfing-related accidents: epidemiology and prevention. http://blog.surf-prevention.com/2009/01/21/surfingrelated-accidentsepidemiology-and-prevention/

Beratan, K.K., Osborne, R.H., 1987. Frequency and demographic aspects in shallow-water diving accidents in southern California. In: Osborne RH (ed) Shallow-water diving accidents at southern California ocean beaches: demographic, sedimentologic, medical, legal and management perspectives. University of Southern California, Los Angeles, CA.

Bradstreet, A.J., Brander, R.W., McCarroll, J.R., Brighton, B., Howes, D.D., Drozdzewski, D., Sherker, S., Turner, I.L., Roberts, A., MacMahan, J.H., 2014. Rip Current Survival Principles: Towards Consistency. Journal of Coastal Research, 72, 85-92.

Brander, R.W., 2018. Beach Safety Research. In: The Encyclopedia of Coastal Science (Ed. C. Finkl), Kluwer Academic Publishers.

Brannstrom, C., Trimble, S., Santos, A., Brown, H.L., Houser, C., 2014. Perception of the rip current hazard on Galveston Island and North Padre Island, Texas, USA. Natural Hazards, 72(2), 11231138.

Brannstrom, C., Brown, H.L., Houser, C., Trimble, S., Santos, A., 2015. « You can't see them from sitting here »: Evaluating beach user understanding of a rip current warning sign. Applied Geography, $56,61-70$.

Brander, R.W., Bradstreet, A., Sherker, S., MacMahan, J., 2011. The behavioural responses of swimmers caught in rip currents: new perspectives on mitigating the global rip current hazard. Int. J. Aquatic Res., 5, 476-482.

Brander, R.W., Scott, 2016. Science of the Rip Current Hazard. In: The Science of Beach Lifeguarding: Principles and Practice (Eds. M. Tipton, A. Wooler and T. Reilly). CRC Press, pp. 67-86.

Brander, R.W., MacMahan, J.H., 2011. Future challenges for rip current research and outreach. In: Leatherman, S., Fletemeyer, J. (Eds.), Rip Currents: Beach Safety, Physical Oceanography and Wave Modeling, CRC Press, pp. 1-29.

Brighton, B., Sherker, S., Brander, R., Thompson, M., Bradstreet, A., 2013. Rip current related drowning deaths and rescues in Australia 2004-2011. Nat. Haz. Earth Sys. Sci., 13, 1069-1075. 
Brumaud, S., 2016. Saison touristique 2015 en Aquitaine - La fréquentation des hôtels et campings au beau fixe, INSEE Analyses Nouvelle-Aquitaine, https://www.insee.fr/fr/statistiques/1908387 (in French).

Bruneau, N., Bonneton, P., Castelle, B., Pedreros, R., 2011. Modeling rip current circulations and vorticity in a high-energy meso-environment. J. Geophys. Res. - Oceans 116, C07026, doi:10.1029/2010JC006343.

Bruneau, N., Castelle, B., Bonneton, P., Pedreros, R., Almar, R., Bonneton, N., Bretel, P., Parisot, J.P., Senechal, N., 2009. Field observations of an evolving rip current on a meso-macrotidal welldeveloped inner bar and rip morphology. Cont. Shelf Res., 29, 1650-1662.

Caldwell, N., Houser, C., Meyer-Arendt, K., 2013. Ability of beach users to identify rip currents at Pensacola Beach, Florida. Natural Hazards, 68(2), 1041-1056.

Castelle, B., Scott, T., Brander, R.W., McCarroll, R.J., 2016a. Rip current types, circulation and hazard. Earth-Sci. Rev. 163, 1-21.

Castelle, B., McCarroll, R.J., Brander, R.W., Scott, T., Dubarbier, B., 2016b. Modelling the alongshore variability of optimum rip current escape strategies on a multiple rip-channelled beach. Nat. Haz., 81, 664-686.

Castelle, B., Bujan, S., Ferreira, S., Dodet, G., 2017. Foredune morphological changes and beach recovery from the extreme 2013/2014 winter at a high-energy sandy coast (2017) Marine Geology, 385, 41-55.

Castelle, B., Guillot, B., Marieu, V., Chaumillon, E., Hanquiez, V., Bujan, S., Poppeschi, C., 2018. Spatial and temporal patterns of shoreline change of a 280-km high-energy disrupted sandy coast from 1950 to 2014: SW France. Estuarine, Coastal and Shelf Science, 200, 212-223.

Chang, S.K., Tominaga, G.T., Wong, J.H., Weldon, E.J., Kaan, K.T., Kenneth, T., 2006. Risk factors for water sports-related cervical spine injuries. J Trauma-Inj Infect Crit Care, 60, 1041-1046.

Dalrymple, R.A., MacMahan, J.H., Reniers, A.J.H.M., Nelko, V., 2011. Rip currents. Ann. Rev. Fluid Mech., 43, 551-581.

Dimmick, S., Brazier, D., Wilson, P., Anderson, S.E., 2013. Injuries of the spine sustained whilst surfboard riding. Emerg Radiol, 20, 25-31.

Doelp, M.B., Puleo, J.A., Cowan, P., Arford-Granholm, M., in press. Characterizing surf zone injuries from the five most populated beaches on the Atlantic-fronting Delaware coast: Delaware surf zone injury demographics. The American Journal of Emergency Medicine.

Drozdzewski, D., Shaw, W., Dominey-Howes, D., Brander, R., Walton, T., Gero, A., Sherker, S., Goff, J., Edwick, B., 2012. Surveying rip current survivors: preliminary insights into the experiences of being caught in rip currents. Nat. Haz. Earth Sys. Sci., 12, 1201-1211. 
Drozdzewski, D., Roberts, A., Dominey-Howes, D., Brander, R., 2015. The experiences of weak and nonswimmers caught in rip currents at Australian beaches. Australian Geographer, 46, 15-32.

Dupoux, J.E., Bernard-Catinat, G., Brunel, J.M., 1981. Réactualisation du traitement d'urgence de la noyade. Bordeaux Méd, 14, 1095-100 (in French).

Gensini, V.A., Ashley, W.S., 2009. An examination of rip current fatalities in the United States. Nat. Haz., 54, 159-175.

Gilchrist, J., Branche, C., 2016. Lifeguard Effectiveness. In: Tipton, M., Wooler, A., Ed. The Science of Beach Lifeguarding. Boca Raton: CRC Press.

Hay, C.S.M., Barton, S., Sulkin, T., 2009. Recreational surfing injuries in Cornwall, United Kingdom. Wilderness Environ Med, 20, 335-338.

Hatfield, J., Williamson, A., Brander, R.W., Sherker, S., Hayen, A., Dunn, N., 2012. Development and evaluation of campaigns to reduce rip current-related beach drowning in Australia, Injury Prevention, 18, A135.

Heggie, T.W., Caine, D.J., 2012. Epidemiology of Injury in Adventure and Extreme Sports. Med Sport Sci. Basel, 58, 80-97.

Houser, C., Brander, R., Brannstrom, C., Trimble, S., Flaherty, J., 2016. Case study of rip current knowledge amongst students participating in a study abroad program. Frontiers: The Interdisciplinary Journal of Study Abroad, 28, 42-60.

Houser, C., Trimble, S., Brander, R., Brewster, B. C., Dusek, G., Jones, D., Kuhn, J., 2017. Public perceptions of a rip current hazard education program:"Break the Grip of the Rip!". Natural Hazards and Earth System Sciences, 17(7), 1003-1024.

Lapaty, X., 2004. Les accidents de plage sur le littoral aquitain, au cours des été 1999 et 2000: épidémiologie générale et proposition de prevention des traumatismes du rachis. MSc. Thesis, Université Bordeaux 2, 91p (in French).

Lushine, J.B., 1991. A study of rip current drowning and related weather factors. Natl. Wea. Dig., 16, $15-31$

MacMahan, J.H., Thornton E.B., Reniers, A.J., 2006. Rip current review, Coastal Eng., 53(2), 191-208.

Masselink, G., Short, A.D., 1993. The effect of tide range on beach morphodynamics and morphology: a conceptual beach model. J. Coast. Res., 9(3), 785-800.

Masselink, G., Castelle, B., Scott, T., Dodet, G., Suanez, S., Jackson, D., Floc'h, F., 2016. Extreme wave activity during 2013/2014 winter and morphological impacts along the Atlantic coast of Europe. Geophys. Res. Let., 43, 2135-2143, doi: 10.1002/2015GL067492.

McCarroll, R.J., Brander, R.W., MacMahan, J.H., Turner, I.L., Reniers, A.J.H.M., Brown, J.A., Bradstreet, A., Sherker, S., 2014. Evaluation of swimmer-based rip current escape strategies. Nat. Haz., 71, 1821-1846. 
McCarroll, R.J., Castelle, B., Brander, R.W., Scott, T., 2015. Modelling rip current flow and bather escape strategies across a transverse bar and rip channel morphology. Geomorphology, 246, 502-518.

McKay, C., Brander, R.W., Goff, J., 2014. Putting tourists in harms way - Coastal tourist parks and hazardous unpatrolled surf beaches in New South Wales, Australia. Tourism Management, 45:71-84.

Menezes, R.A., Costa, R.V.C., 1972. Resgate e recuperação de 12.037 afogados. J Bras Med, 9, 50-64.

Moran, K., Webber, J., Stanley, T., 2017. The 4Rs of aquatic rescue: educating the public about safety and risks of bystander rescue. International Journal of Injury Control and Safety Promotion, 24(3):396-405.

Morgan, D., Ozanne-Smith, J., 2013. Surf Lifeguard Rescues. Wilderness \& Environmental Medicine, $24,285-290$.

Moulton, M., Dusek, G., Elgar, S., Raubenheimer, B., 2017. Comparison of Rip Current Hazard Likelihood Forecasts with Observed Rip Current Speeds. Wea. Forecasting, 32, 1659-1666.

Muller, M.W., 2018. Beach replenishment and surf zone injuries along the coast of Delmarva, USA, In Ocean \& Coastal Management, 151, 127-133,

Nathanson, A.T., 2013. Surfing Injuries. In: Mei-Dan, O., Carmont, M., Ed. Adventure and Extreme Sports Injuries. Springer, London.

Pikora, T., Braham, R., Mills, C., 2012. The epidemiology of injury among surfers, kite surfers and personal watercraft riders: Wind and waves. In Heggie, T.W., Caine, D.J., Ed.), Epidemiology of Injury in Adventure and Extreme Sports, Medicine and Sports Science (Vol. 28), Karger, A.G., Switzerland, pp. 80-97.

Puleo, J.A., Hutschenreuter, K., Cowan, P., Carey, W., Arford-Granholm, M., McKenna, K.K., 2016. Delaware surf zone injuries and associated environmental conditions. Nat. Haz., 81, 845-867.

RNLI, 2014. Operational Statistics. http://rnli.org/aboutus/aboutthernli/Documents/opsstatsreport.pdf, pp 46

Roberts, D.J., Ouellet, J.F., McBeth, P.B., Kirkpatrick, A.W., Dixon, E., Ball, C.G., 2014. The "weekend warrior": fact or fiction for major trauma? Can J Surg., 57(3), E62-8.

Robles, L.A., 2006. Cervical spine injuries in ocean bathers: wave-related accidents. Neurosurgery, 58, 920-923.

Scott, T.M., Masselink, G., Austin, M.J., Russell, P., 2014. Controls on macrotidal rip current circulation and hazard. Geomorphology, 214, 198-215.

Sherker, S., Brander, R.W., Finch, C., Hatfield, J., 2008. Why Australia needs an effective national campaign to reduce coastal drowning. Journal of Science and Medicine in Sport, 11, 81-83.

Sherker, S., Williamson, A., Hatfield, J., Brander, R., Hayen, A., 2010. Beachgoers' beliefs and behaviours in relation to beach flags and rip currents. Acc. Anal. Prev., 42, 1785-1804. 
Short, A.D., Weir, A., 2016. Beach types, hazards and risk assessment. In: Tipton, M., Wooler, A., Ed. The Science of Beach Lifeguarding. Boca Raton: CRC Press.

Short, A.D., Brander, R.W., 2014. Beach Hazard and Risk Assessment. In: Bierens, J., Ed. Drowning. Springer, Berlin, Heidelberg.

SLSA, 2017. National Coastal Safety Report 2017. SLSA: Sydney. https://sls.com.au/slsa-ar-2017/

USLA, 2015. 2010-2014 National Lifesaving Statistics.

\section{http://arc.usla.org/Statistics/current.asp?Statistics=5}

Van Leeuwen, McCarroll, J. R., Brander, R.W., Turner, I.L., Power, H., Bradstreet, A., 2016. Examining rip current escape strategies in non-traditional beach morphologies. Nat. Haz., 81, 145-165.

Williamson, A., Hatfield, J., Sherker, S., Brander, R., Hayen, A., 2012. A comparison of attitudes and knowledge of beach safety in Australia for beachgoers, rural residents and international tourists. Aust. N.Z. J. Pub. Health, 36, 385-391.

Williamson, A., 2006. Feasibility study of a water safety data collection for beaches. J Sci Med Sport., 9, 243-248.

West, N., 2005. Beach Use and Behaviors. In: Schwartz, M.L., Ed. Encyclopedia of Coastal Science. Encyclopedia of Earth Science Series. Springer, Dordrecht.

Woodward, E., Beaumont, E., Russell, P., Wooler, A., Macleod, R., 2013. Analysis of Rip Current Incidents and Victim Demographics in the UK. Journal of Coastal Research, SI 65, 850-855. 


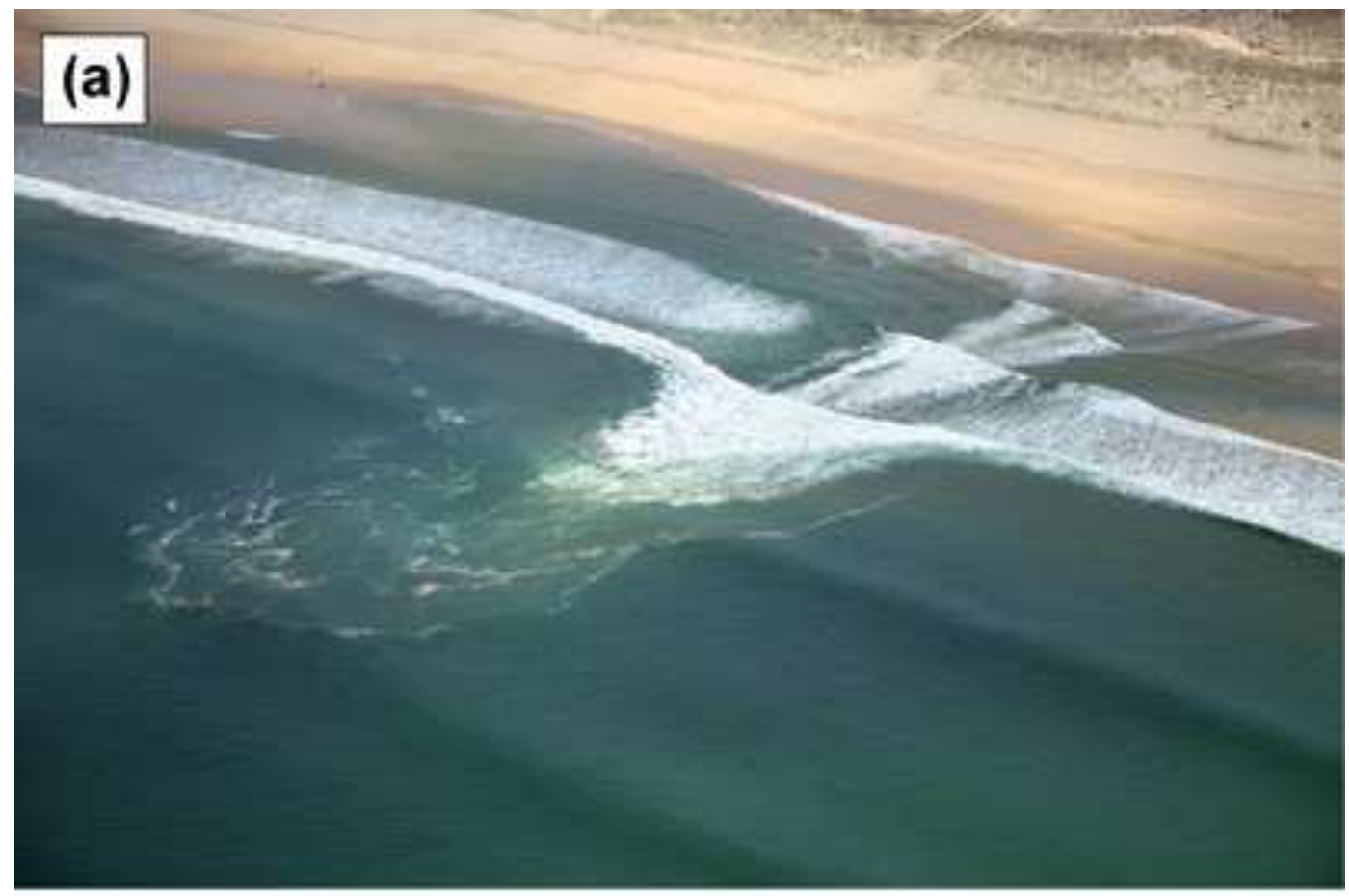

(b)

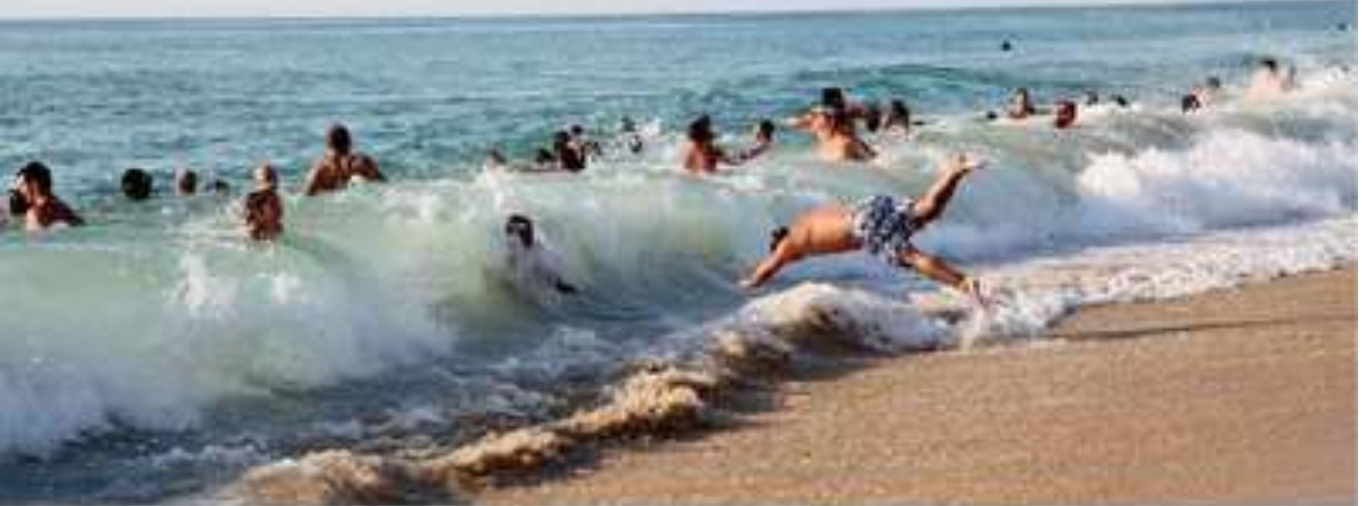

(c)

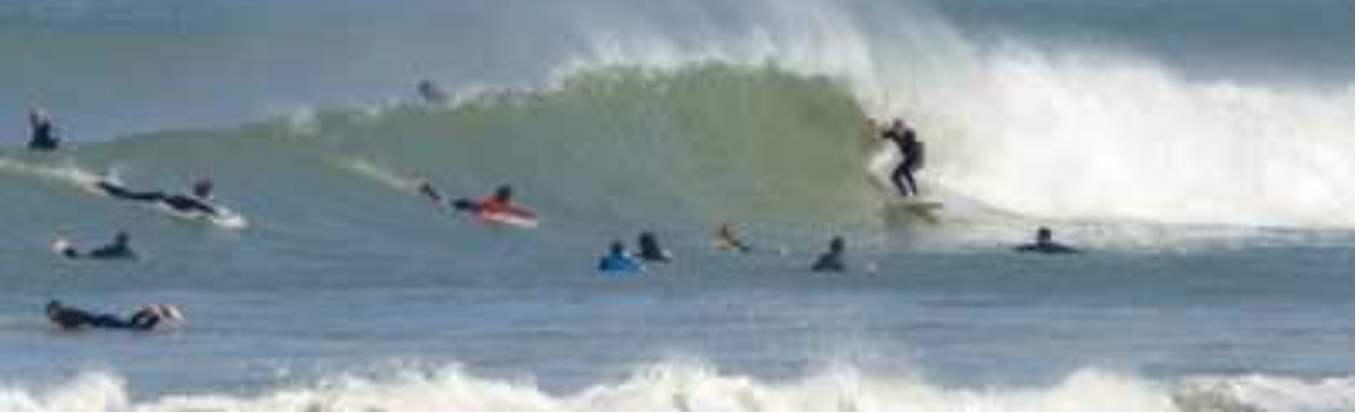



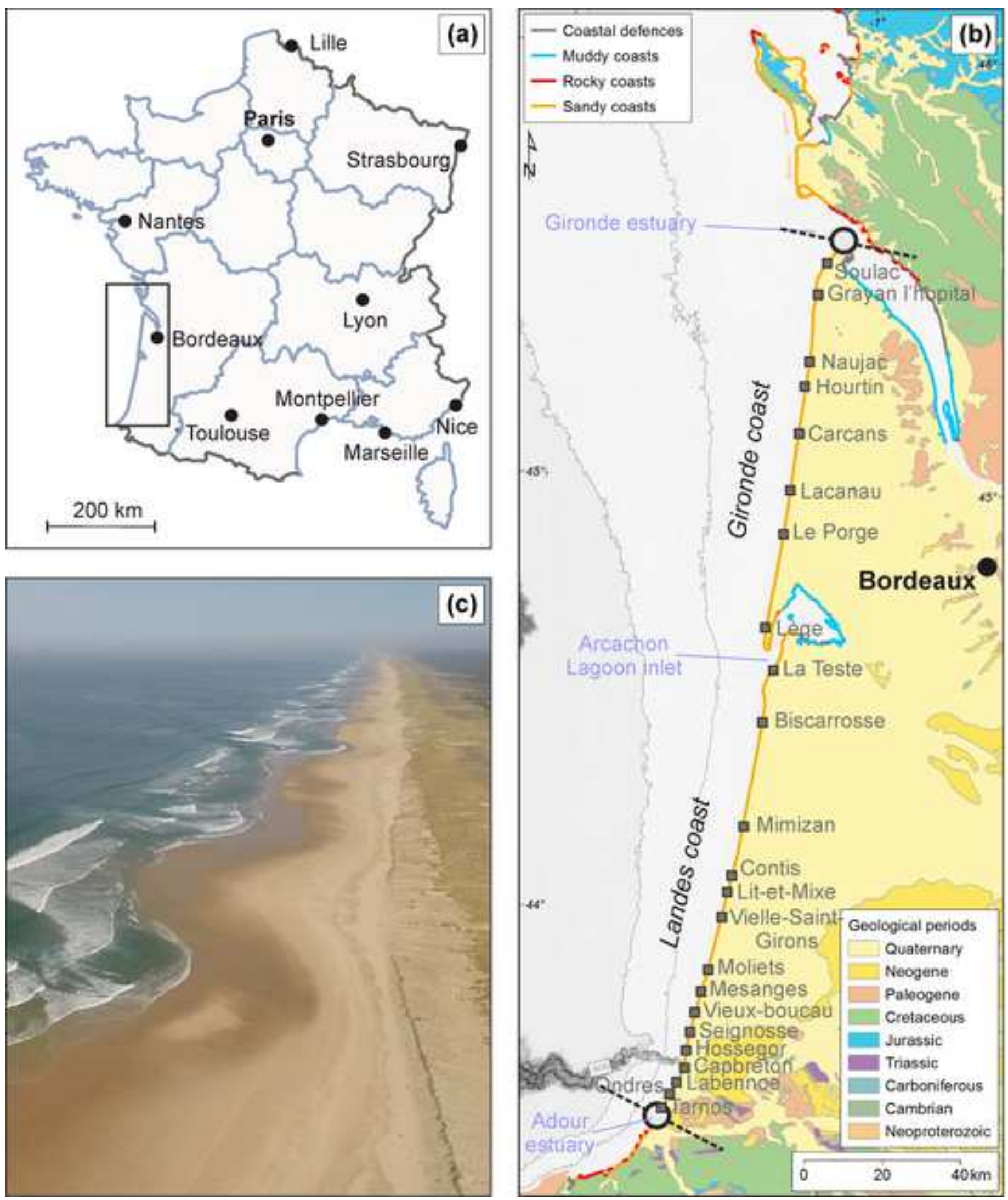
Figuttegte: $1 \underline{1}$ / $/ \underline{0} \underline{8} / 20 \underline{1} \underline{5}$

Lifeguard's: Northern beach station

Flag: $\square \mathrm{G} \quad \nabla \mathrm{Y} \quad \square \mathrm{R}$
Form \#: 26

Start: $1 \underline{7} \mathrm{~h} 1 \underline{5}$ End: $1 \underline{8} \mathrm{~h} \underline{0} \underline{0}$

Patrolled hour $\nabla$ Yes $\square$ No

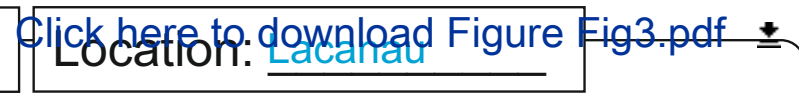
Accident on the beach $\square$ Yes $\square$ No Pattroled area $\square$ Yes $\square$ No Bathing zone $\square$ Yes $\square$ No

\section{IDENTITY}

NAME: $\mathrm{XXXXXXXXXX}$

Age: $29 \quad M \square \quad F \nabla$

Adress: 23, Second Street, 33600

\section{ACCIDENT}

Activity: $\square$ Wading / swimming $\square$ Surfing $\square$ Bodyboarding $\quad \square$ Shorebreak $\square$ other

- Accident description: In the bathing zone she got pounded by a shorebreak, swallowed a little bit of water. She was able to go back to shore alone.

Saved by: $\square$ Lifeguard $\square$ Helicopter $\square$ Boat $\square$ Bystander $\quad \square$ Alone $\square$ Other

Faint:: $\square$ Yes $\nabla$ No

Desease: $\square$ Yes $\square$ No

\section{MEDICAL REVIEW}

- Drowning stage $\quad \square 1 \quad \square / 2 \quad \square 3 \quad \square 4$

Traumatology:

\begin{tabular}{|l|l|l|l|l|l|}
\multicolumn{2}{c}{ Head } & \multicolumn{1}{c}{ Spine } & \multicolumn{1}{c|}{ Limb } & \multicolumn{1}{c|}{ Thorax } \\
\hline Contusion & & & & & \\
\hline Wound & & & & \\
\hline Fracture & & & & & \\
\hline Luxation & & & & &
\end{tabular}

Other

Summary: The victim is shocked, with moderate respiratory impairment

\section{VITAL SIGNS}

Conscious

Breathing

Pulse:
Initial loss of consciousness

Labored $\nabla$ Yes $\square$ No
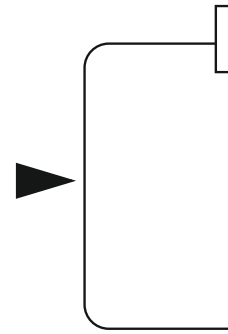

\begin{tabular}{l}
\hline \multicolumn{1}{c|}{ SEVERITY } \\
$\square$ No severity $\quad \square$ Mild severity \\
$\square$ Severe $\quad \square$ Very severe \\
$\square$ Fatal
\end{tabular}

\section{$\square \mathrm{O}_{2} \quad \square$ Cervical collar}
CARE
$\square$ Upper airway $\square$ Ventilation release

Chest compression

\section{TRANSPORT FROM THE BEACH}

$\square$ Fire $\square$ Emergency $\square$ Helicopter $\square$ Private $\square$ On their $\square$ Local doctor brigade Medical Services Ambulance own

Towards: $\square$ Hospital $\square$ Clinic $\square$ Doctor office $\square$ No transportation

$\square$ Medical committee $\square$ REFUSAL 
Figure 4 Injury $n$ €誨2月ere to

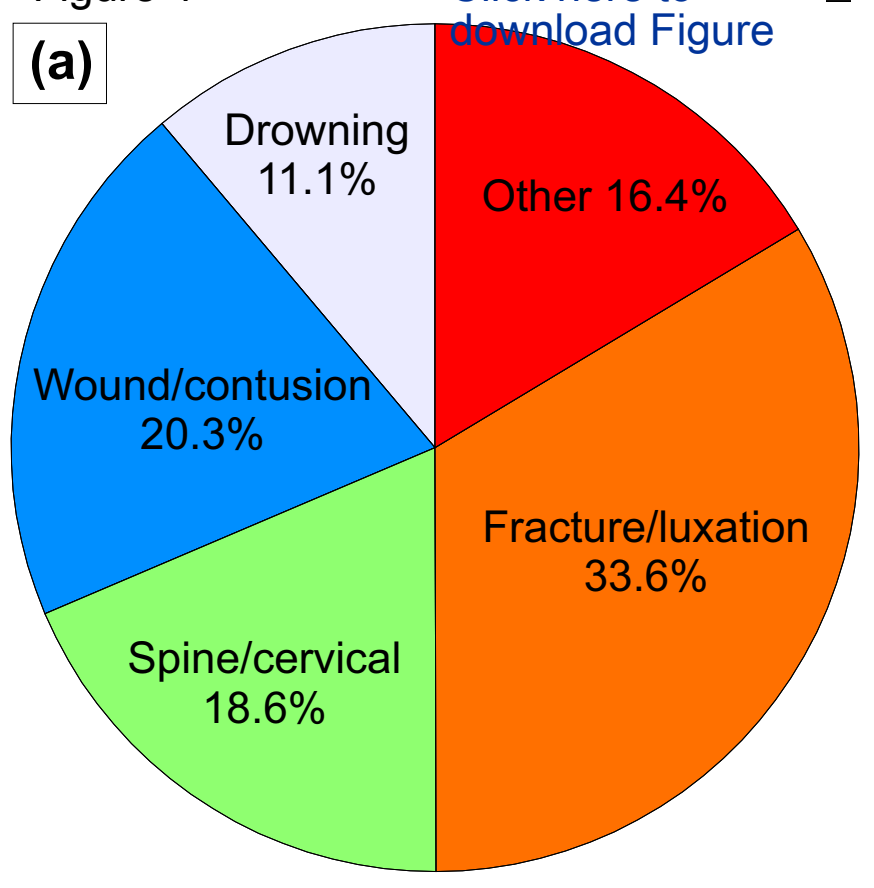

Primary cause $n=2523$

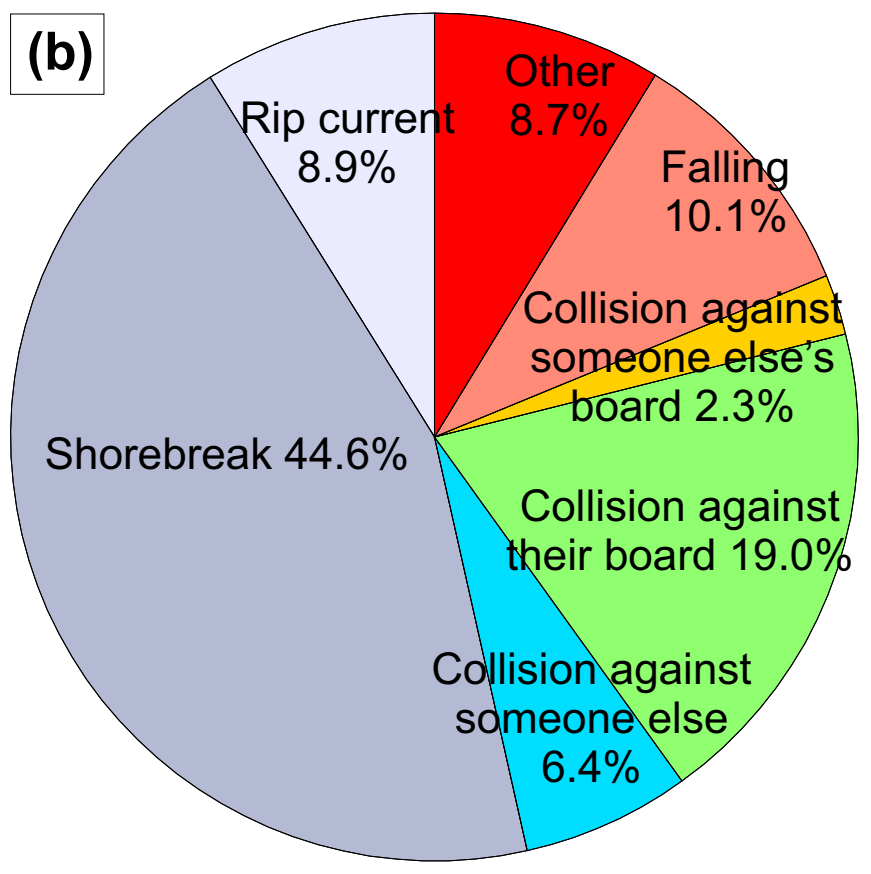

Activity $n=2523$

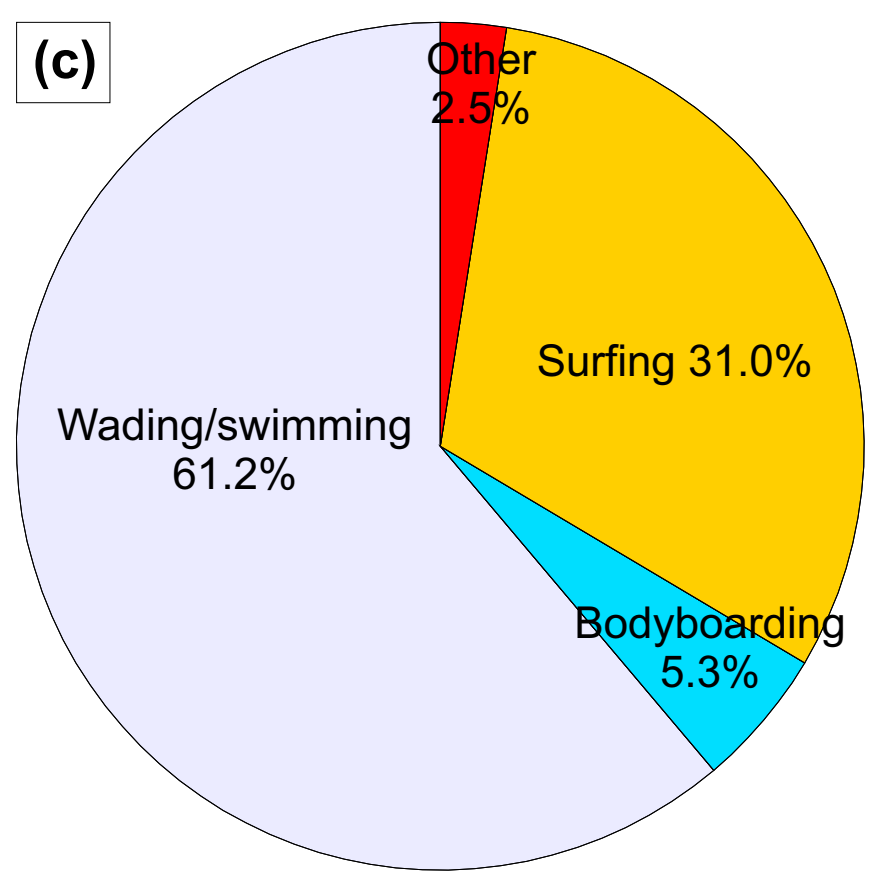


Figure 5

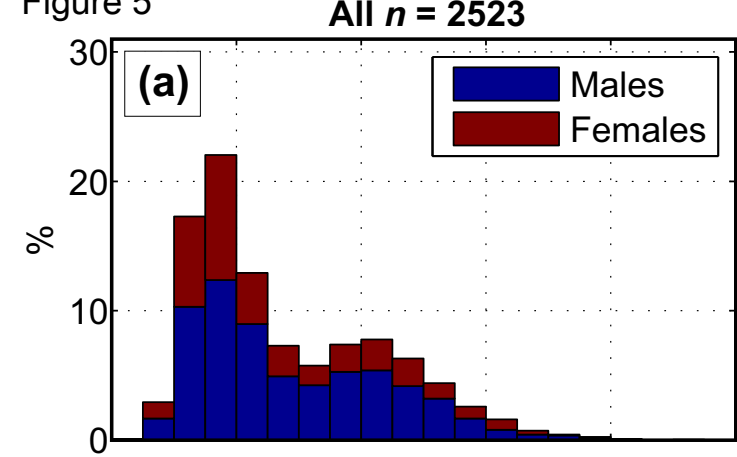

Surfers only $n=783$

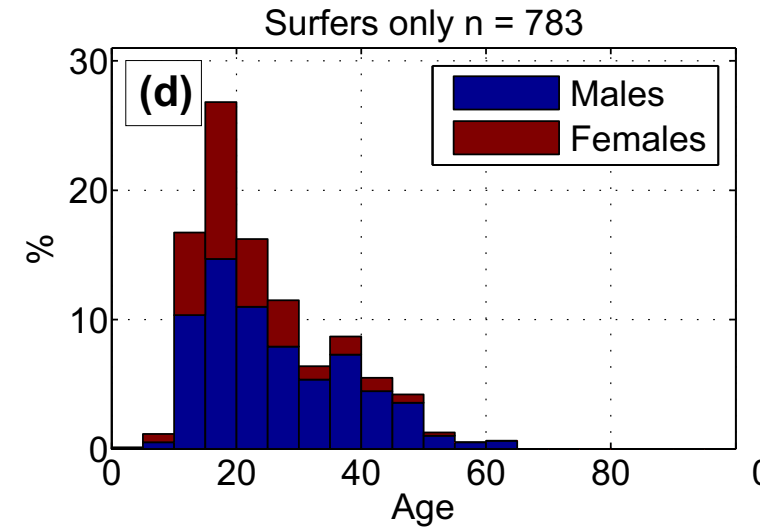

Wading/swimming only $n=1543$

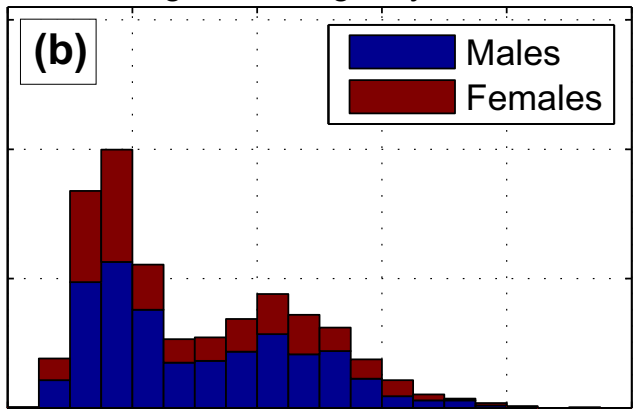

Spinal/cervical only $n=470$

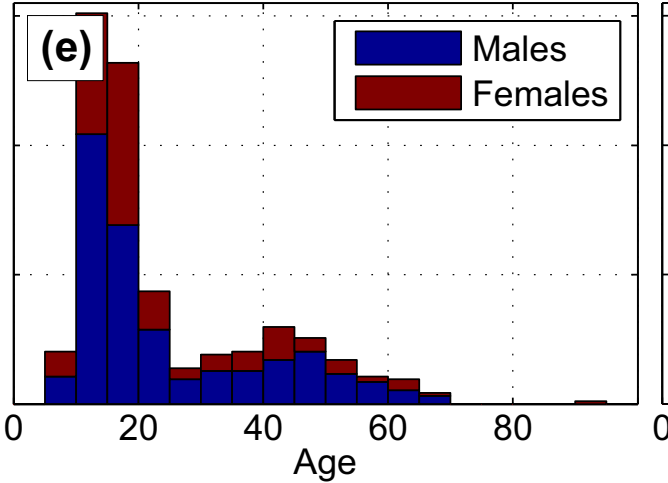

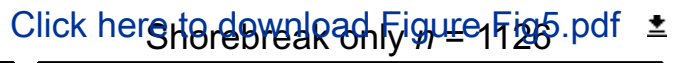

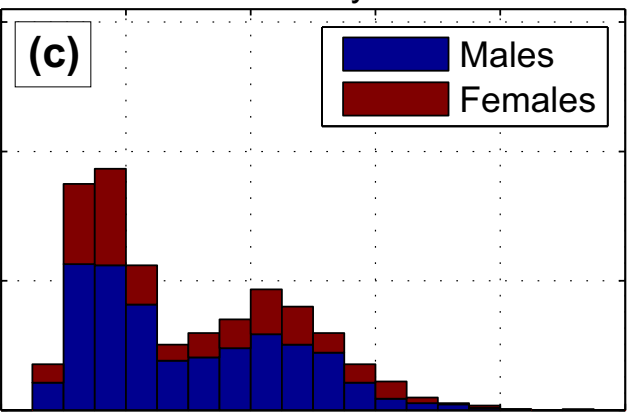

Drowning only $\mathrm{n}=281$

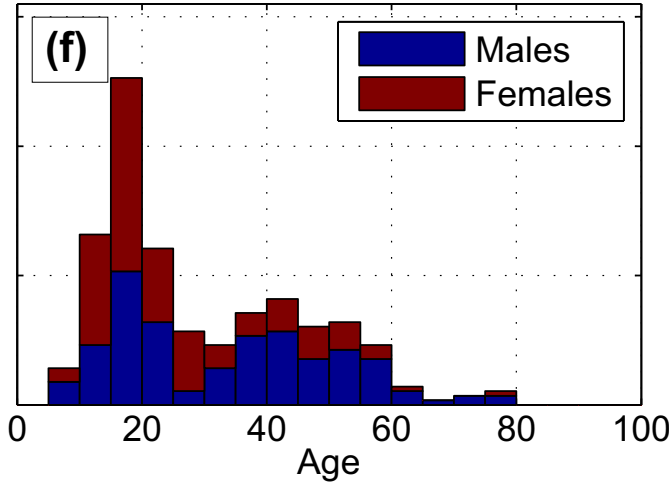



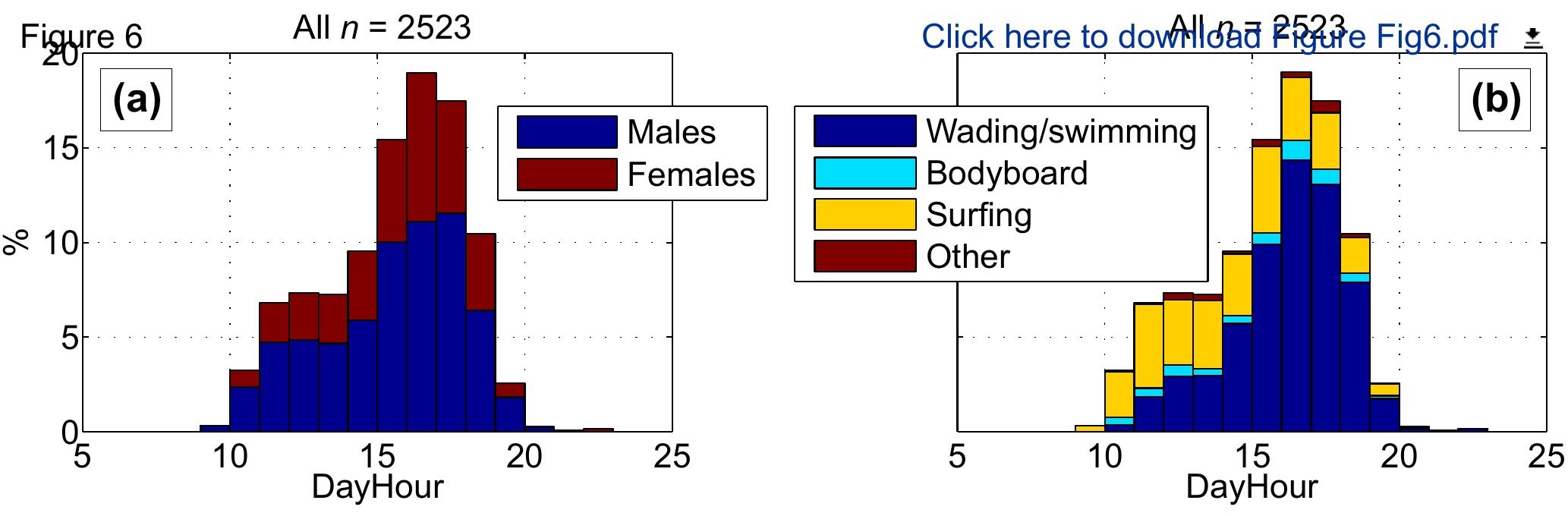
Figtheowning $n=281$

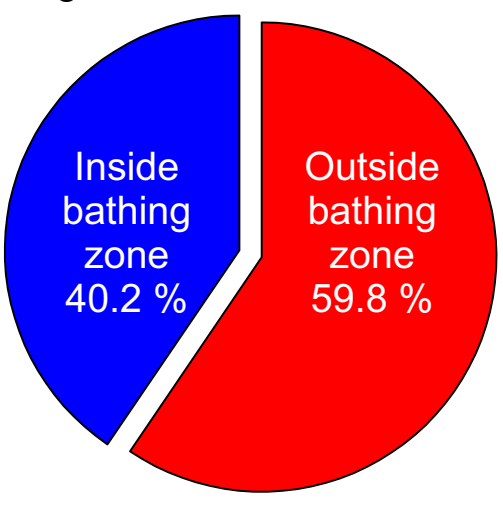

Spine/cervical $n=470$

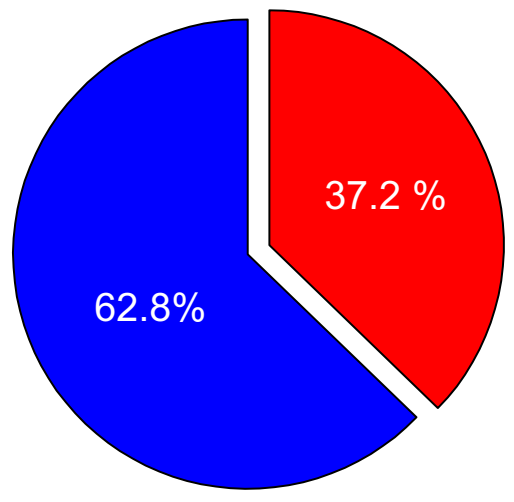

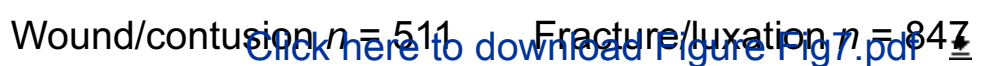
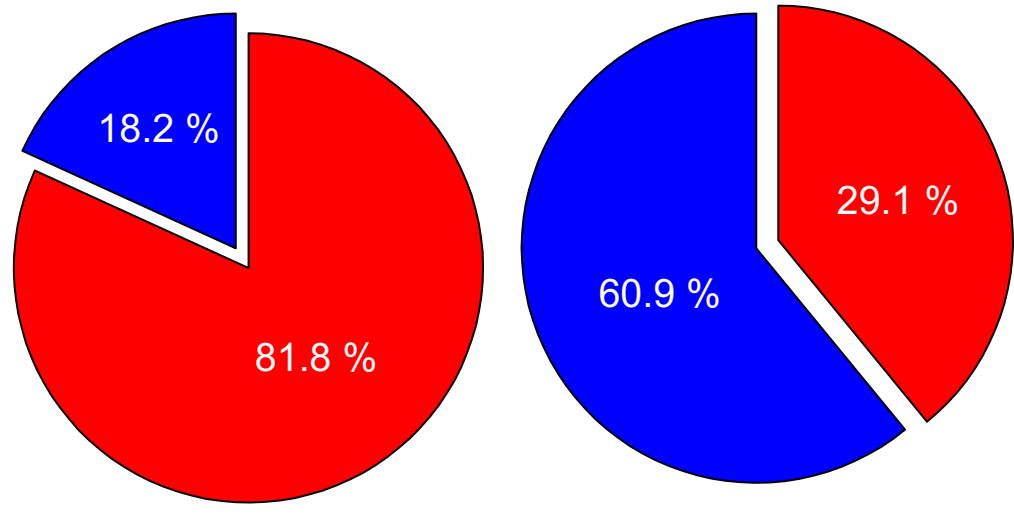


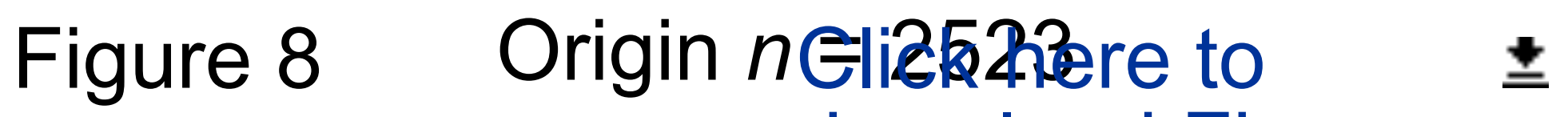
download Figure

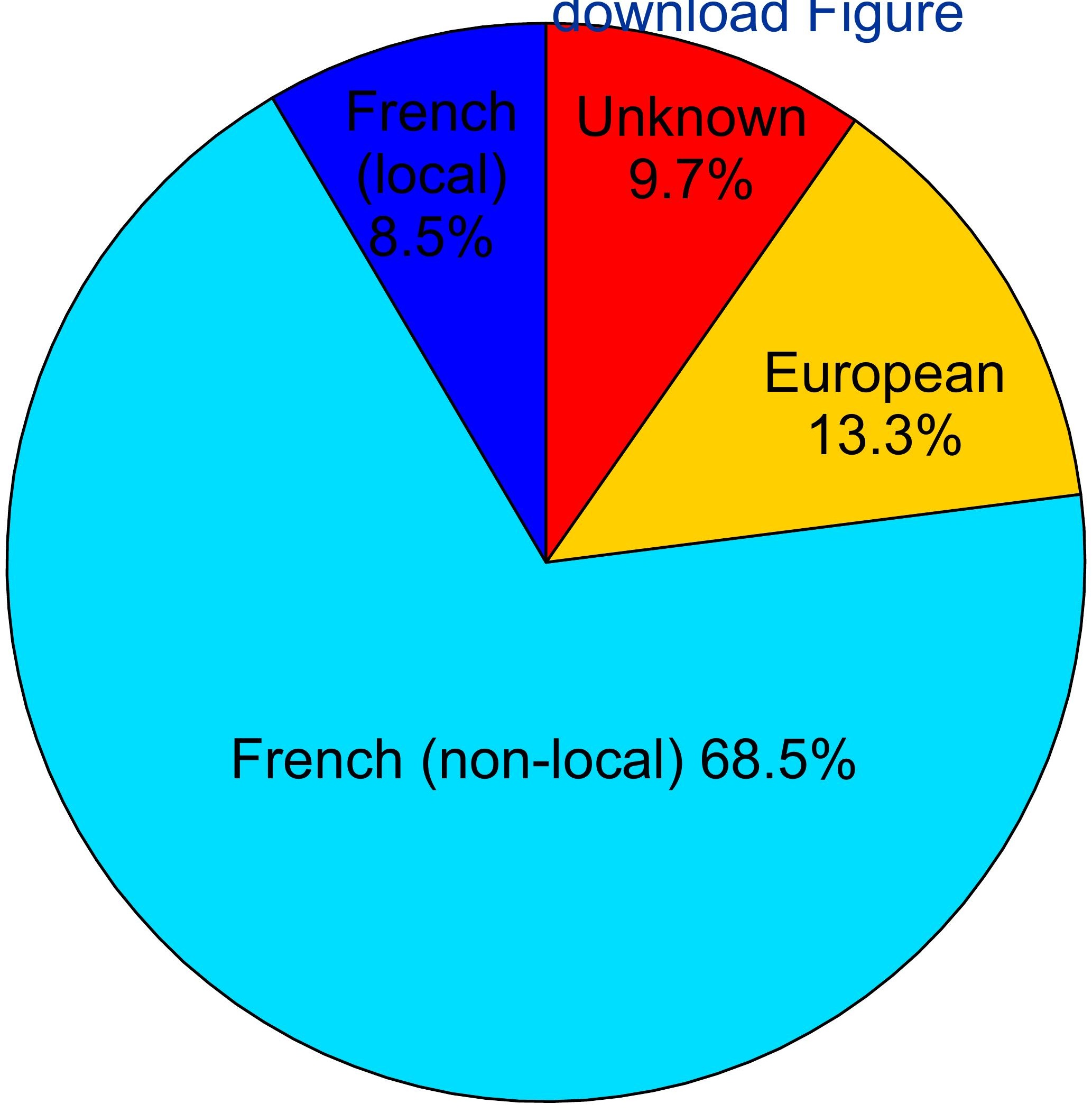


Figure 9

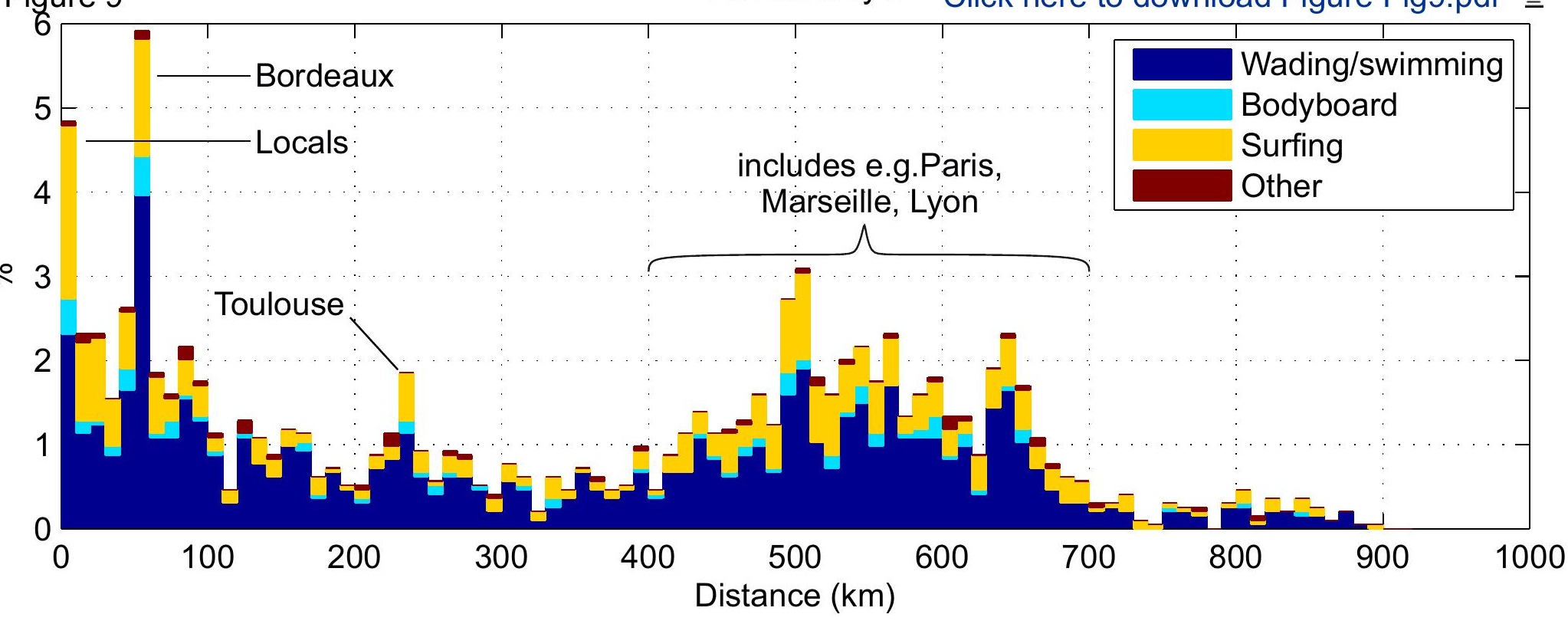

